\title{
CARPENTIER BÍBLICO Y DANTESCO: LA MALINCHE Y RAJAB EN LA APRENDIZ DE BRUJA
}

\section{A BIBLICAL AND DANTEAN CARPENTIER: LA MALINCHE AND RAHAB IN LA APRENDIZ DE BRUJA}

\author{
Esteban Crespo-Jaramillo \\ Yale University \\ esteban.crespo@yale.edu \\ orcid: 0000-0003-4882-6197
}

\begin{abstract}
RESUMEN: La obra teatral La aprendiz de bruja caracteriza a su protagonista, la Malinche, sirviéndose de la historia bíblica poco conocida de Rajab en la conquista de Jericó. Al estudiar a Rajab en este contexto, en apariencia inusitado, propongo una nueva filiación dantesca en Carpentier y la articulo según los modos de reescritura y el diseño argumental de la obra. Éstos no sólo suponen un empleo heterodoxo de los modelos, sino que además cuestionan cómo la Commedia y el libro de Josué representan a Rajab. Así, la relectura del coherente paralelismo que Carpentier instituye entre Rajab y la Malinche aporta interpretaciones vigentes en discusiones sobe historia, literatura y el pensamiento crítico contemporáneo.
\end{abstract}

Palabras clave: Biblia; Divina comedia; reescritura; heterodoxia; literatura colonial.

Aвstract: In the play La aprendiz de bruja the figure of its protagonist, la Malinche, is projected on to the little-known biblical story of Rahab and her role in the conquest of Jericho. In this paper I show that, with its rewriting of previous texts, the play includes an instance, not previously noticed, of Carpentier reading Dante. It also demonstrates how the overall design of the work entails not only an unorthodox use of literary sources, but also a questioning of the way in which both the Commedia and the book of Joshua present the figure of Rahab. By studying the parallels that Carpentier establishes between Rahab and la Malinche, the paper contributes to discussions about history, literature, and contemporary critical thought.

Keywords: Bible; Divine Comedy; rewriting; heterodoxy; colonial literature.

Recepción: 11 de noviembre de 2019; aceptación: 15 de septiembre de 2020.

D.R. () 2022. Nueva Revista de Filología Hispánica Licencia Creative Commons Attribution-NonCommercial (CC BY-NC) 4.0 International 
Originalmente escrita en francés y con un título de ascendencia germánica, La aprendiz de bruja, uno de los pocos textos dramáticos que Alejo Carpentier escribió, imita con laxitud la estructura de comedia histórica lopesca y presenta un tema mexica-colonial $^{1}$. Además, el conocidísimo argumento central — la historia de la Malinche y su papel en la conquista de México- es en sí mismo producto de una superposición antigua de mitos, historiografía y traducciones. O para decirlo de otra manera, en $L a$ aprendiz de bruja se encuentra esa imbricación de fuentes, modelos y tradiciones culturales que caracteriza la obra carpenteriana. Pero eso no es todo. A la superposición de versiones que dan forma a la Malinche, La aprendiz de bruja añade un sustrato que la crítica ha pasado por alto: el relato bíblico de Rajab y su función en la conquista de Jericó. Esta afinidad que una obra de teatro escrita en 1956 — publicada póstumamente en 1983establece entre aquella mujer bíblica y esta mujer mesoamericana, contribuye a la disolución de las tipologías con que se suele caracterizar a la Malinche. Tanto por el uso heterodoxo de las fuentes literarias - particularmente la Commedia de Dante, como se verá en detalle- cuanto por la originalidad del personaje bíblico escogido como arquetipo (ni Eva ni María ni Judit, sino Rajab), La aprendiz de bruja termina transformando a su protagonista en un sujeto elocuente, consciente de sí misma y en camino a liberarse de binomios fijos.

Pese a que la persona histórica, llamada Malintzin por sus contemporáneos indígenas (Townsend 2006, p. 12), no dejara textos propios, su voz nos ha llegado por medio de cinco siglos de escrituras y reescrituras ${ }^{2}$. El repertorio es vasto ${ }^{3}$, inclu-

1 Según las Obras completas de Alejo Carpentier (1983b) y GonzÁlez Echevarría (1990), los otros textos dramáticos escritos por Carpentier son: La rebambaramba (ca. 1927) - ballet afrocubano en un acto y dos cuadros; escenario de Alejo Carpentier, música de Amadeo Roldán-; Manita en el suelo (ca. 1960) —ópera bufa, en un acto y cinco escenas; música de Alejandro García Caturla, libreto de Alejo Carpentier-; Un ballet afrocubano (1937) —el milagro de Anaquillé. A esta lista hace falta añadir Les portes du soleil, una ópera moderna en cuatro movimientos, cuyos manuscritos y mecanuscritos reposan en la Fundación Alejo Carpentier. Debo esta información a su bibliotecario, Armando Raggi Rodríguez.

2 Townsend 2006 ofrece el estudio histórico más completo sobre Malintzin hasta el momento, pero véanse también Cypess 1991 y RESTALL 2018. Para un análisis de los códices nahuas, veáse Brotherston 1994.

${ }^{3}$ Lopez 2002, particularmente en la nota 26 (p. 183), presenta un repertorio exhaustivo en el ámbito latinoamericano. 
ye géneros y artes de todo tipo, y el interés no deja de crecer, incluso fuera del ámbito panhispánico ${ }^{4}$. En un fundamental ensayo, Norma Alarcón ofrece su relectura del mito de la Malinche y, además, reorganiza esa plétora de fuentes en tres amplias líneas, análogas a las tres "imaginary Malintzins" que Matthew Restall define (2018, pp. 286-293). Mucho después de que las fuentes coloniales (en español y náhuatl) comenzaran a forjar la leyenda, explica Restall, nació una Malintzin hija del Romanticismo, amorosa y leal, ejemplo de mujer decimonónica ( $p$. 289). Como respuesta a esta figura idealizada, surgió el mito del malinchismo traicionero y expiador, que llegó a término en el siglo XIX, y que incentivó, a su vez, un movimiento modernista reivindicativo de la Malinche en el siglo xx, encabezado por el "neomito" de Octavio Paz (Alarcón 1989, pp. 64-65).

Según estudiosas como Pilar Godayol (2012), las interpretaciones contemporáneas, chicanas y feministas del mito conforman la última y más reciente línea de investigación ${ }^{5}$. Según este esquema, La aprendiz de bruja debería acompañar a clásicos contemporáneos suyos, como Visión de Anáhuac (1516) (1917) o El laberinto de la soledad (1950). Y, en efecto, Carpentier parece responder, junto con Octavio Paz, al encargo de Alfonso Reyes (1953) sobre la Malinche: "no le neguemos la evocación, no desperdiciemos la leyenda" (p. 62). También repite para su protagonista el nombre que Reyes le dio, doña Marina. Sin embargo, la respuesta teatral de Carpentier, publicada treinta años después de ser escrita (y durante los primeros años de la Revolución cubana), calza menos con sus contemporáneos de la posguerra que con relecturas posteriores, incluso con las más actuales.

Por su heterodoxia intertextual, La aprendiz de bruja ofrece una Malintzin que demuestra ser narradora de sí misma antes que la legendaria traidora-traductora. De mito maniqueo o misterioso, se transforma en una persona compleja. Consciente del trágico poder con que cargan sus palabras, en el primer acto doña Marina discrepa de los halagos de un fraile mercedario, Bartolomé de Olmedo, y dice: “¿Por qué tanta confianza? ¿Por qué tantas tareas abrumadoras...? Me hubiese conformado

${ }^{4}$ La estudiosa italiana Emilia Perassi (2005) recuerda las "rivisitazioni della figura di doña Marina proposte da Celestino Gorostiza ne La Malinche, del 1958, e da Rodolfo Usigli, in Corona de fuego del 1960" (p. 107).

5 Sobre esta última cuestión, véase Pratt 1993. 
con el simple papel de hembra" (Carpentier 1983a, p. 73) Hacia el final de la obra, doña Marina impreca al mismo fraile Olmedo, casi irónica:

¿Queréis hacer de mí una santa? (Se levanta.) Una aureola es lo único que le falta a la guardarropía que me prestan. ¿Cómo queréis verme? ¿Como heroína? (Interpreta cada uno de los papeles.) Miradme con los ojos de vuestros soldados... ¿Como traidora detestable? Preguntádselo a las gentes de la costa... ¿Como enfermera sublime? Que os respondan los lisiados de la guerra... ¿Como puta entregada al enemigo? Con pronunciar mi nombre en el mercado de México... ¿Santa, además? ¿Por qué no? Bastaría con que se hablara un poco de mí en Roma (p. 140).

En lugar de hablar por o sobre ella, en su artefacto teatral Carpentier da voz a la Malinche, y aprovecha esa voz para construir una conciencia poliédrica o de bricoleur, dirigida hacia el abandono de oposiciones binarias ${ }^{7}$. No vemos un objeto de representación solamente, sino también un sujeto de articulación y elocuencia ${ }^{8}$. Como Gloria Anzaldúa en su esencial libro Borderlands/La frontera: The new mestiza, esta doña Marina exige algo parecido, también en primera persona: "don't give me your tenets and your laws. Don't give me your lukewarm gods. What I want is an accounting with all three cultures-white, Mexican, Indian" (1987, p. 22). Así, en un gesto altruista, La aprendiz de bruja confronta las "guardarropías", las interpretaciones que otros han adjudicado a la Malinche. Aun de manera ficticia e incompleta, la pieza teatral le pregunta “¿quién eres?” y le permite narrarse a sí misma más allá de tipologías impuestas9.

Esas tipologías son producto de la acumulación de fuentes durante siglos, como bola de nieve o proceso serial (Godayol

${ }^{6}$ A partir de aquí, tras cada cita o referencia evidente a La aprendiz de bruja, anotaré entre paréntesis la página o páginas de la edición correspondiente a 1983a.

7 Para una lectura de la Malinche desde la filosofía de la tecnología y el feminismo, véase Donna Haraway (2016, p. 58) y su cyborg, quien es, entre otras cosas, "a creature of social reality as well as a creature of fiction" (p. 5).

${ }^{8}$ Carpentier explica por qué escogió el teatro para esta cuestión: "el tema que me urgía tratar, en fecha reciente, necesitaba del diálogo... necesitaba el coloquio, el choque de oposiciones, la controversia" (apud BÁEz-JorGE 1998, p. 102).

${ }^{9}$ Sobran las implicaciones éticas que emergen cuando uno se narra a sí mismo, o cuando lo hace "el otro". Véanse ButLer 2005 y Cavarero 2000. 
2012). Pero todas comparten el cuento y el recuento de la historia de Malinche, Malinalli, Mariana, Malintzin o Marina, ese individuo cuyo personaje histórico conocemos a través de varios velos, el primero de los cuales es su nombre múltiple ${ }^{10}$. Todas cuentan la historia de una mujer americana que - entregada a los castellanos, bautizada Marina, antes conocida en náhuatl como tenepal, 'la elocuente' (Cypess 1991, p. 181; Chimalpahin's conquest... 2010, p. 32), y ahora ante todo como la Malinchesirvió de intérprete a Hernán Cortés en sus diálogos con los mexicas y terminó siendo puente entre al menos tres culturas. Malintzin acabó representando la encrucijada del polémico dilema moral que siguen suscitando las estructuras de género, el mestizaje en América y el poder de la palabra.

Pese a que muchos hayan andado este camino de tantas maneras, La aprendiz de bruja es el primer texto que encuentra en el "presente momento del pasado" de Rajab a una contemporánea arcaica de Malintzin ${ }^{11}$. Para decirlo de otra forma, la pieza teatral, a la vez contemporánea y anacrónica, logró ver entre la penumbra de su presente que en el distante libro de Josué aparece uno de los primeros personajes "malinchistas" de Occidente, Rajab ${ }^{12}$. Según cuenta el libro bíblico (Josué 2:124; 6:17-25), Rajab fue una mujer canaanita, tradicionalmente considerada meretriz, que traicionó a su pueblo, protegió a los espías del conquistador extranjero — que era israelita- y ayudó, por tanto, en la destrucción y el saqueo de su pueblo sagrado, Jericó. Como recompensa a su lealtad, Josué, líder de los conquistadores, salvó a Rajab, a sus padres y a sus hermanos, y así Rajab y los suyos terminaron viviendo como forasteros entre

10 Siguiendo a Townsend (2006, pp. 12-13), sobre todo llamaré al personaje histórico por su nombre náhuatl, Malintzin, pero también Malinche; al personaje de La aprendiz de bruja, Marina.

11 En perspectiva poscolonial, RowLeTt (2000) también vincula a Rajab con una nativa en un ámbito de conquista, la Pocahontas de Disney.

${ }^{12}$ Estoy pensando en la formulación de "lo contemporáneo", de GioRgio Agamben: "quella relazione col tempo che aderisce a esso attraverso una sfasatura e un anacronismo" (2008, p. 9); "Può dirsi contemporaneo soltanto chi non si lascia accecare dalle luci del secolo e riesce a scorgere in esse la parte dell'ombra, la loro intima oscurità.” (p. 13; cursivas añadidas). Pero también pienso en el ensayo de Borges, "Kafka y sus precursores", y en el de T.S. Eliot (1928 [1920]), que concluye diciendo: "And he [the poet] is not likely to know what is to be done unless he lives in what is not merely the present, but the present moment of the past, unless he is conscious, not of what is dead, but of what is already living" (p. 59). 
los invasores. Bastaría con sustituir Rajab por Malintzin, Josué por Cortés, israelitas por españoles y Jericó por Cholula, y sin modificar un punto de la trama estaríamos ya no entre las tribus prebabilónicas de Israel, sino entre los mexicas de la Triple Alianza de 1519. Si seguimos la pieza teatral, este juego de la historia podría entenderse como un peculiar caso secular de tipología teológica, o incluso de profecía ecuménica. Al final, la mujer que ayuda al colonialista recién llegado y consigue un puesto en la nueva sociedad constituye un personaje tipo en los relatos de conquista (Havrelock 2017, p. 254).

Pero hay paralelismos no solamente en este esbozo argumental. En los dilemas éticos que el relato doble despierta y en el componente perspectivista que condiciona tales dilemas, la coincidencia germinal supone un terreno fértil para la imaginación literaria. Carpentier se sirve de esto en su lectura escéptica de Dante y en su rehabilitación de preguntas heterodoxas, probablemente presentes ya en el texto hebreo, pero no en los discursos sobre Malintzin ${ }^{13}$. El escenario privilegiado para estas negociaciones en la pieza teatral es la conciencia ficticia de doña Marina, pues se declara contemporánea de Rajab y, al final, llega a reconocerse en ella. El personaje de Cortés, de hecho, ordena que otro personaje, el fraile Bartolomé de Olmedo, acompañante en esas primeras expediciones, leyera a Marina "todos los pasajes de las Escrituras que conciernen a Josué" (p. 51). En esos pasajes bíblicos, Rajab se dirige al rey de Jericó y, muy prolijamente, a los espías de Josué. Y siempre habla por y para sí misma o, como diría Anzaldúa, "to fight for her own skin and a piece of ground to stand on, a ground from which to view the world-a perspective" (1987, p. 23). Así se explica algo que la crítica carpenteriana no ha logrado explicarse: La aprendiz de bruja no caracteriza a doña Marina como madre. Según el texto bíblico, Rajab tampoco lo fue, pero la tradición igualmente la tipifica como antepasado de Cristo (Nowell 2008; Robinson 2009, p. 258 ${ }^{14}$; Weren 1997).

En las fuentes semíticas Rajab aparece sólo en Josué; ni los textos apócrifos del Antiguo Testamento ni la literatura coránica la mencionan. Las fuentes cristianas sí la registran, pero sin

13 JACKSON 2012 ofrece una original caracterización de la Rajab de Josué en clave cómica, subversiva y feminista.

${ }^{14}$ Rajab aparece en la genealogía de Cristo (Mateo 1:1-17). Véase también LyONS 2008. 
abundar en ella, y a veces de maneras contradictorias (Robinson 2009, p. 257). Si no fuera porque Dante restauró al personaje en un cielo de su Paradiso, sorprendería que el escritor cubano se haya servido de Rajab, muy poco frecuentada también en la tradición literaria occidental - particularmente en Latinoamérica-, para modelar a su Marina y caracterizar su aparición escénica ${ }^{15}$. Pero Rajab resulta además una precursora que transforma las referencias literarias de La aprendiz de bruja - germánicas, hispánicas y americanas- gracias a su afinidad y a su negociación con la Commedia dantesca. Olvida las usuales oposiciones binarias impuestas sobre Malintzin en cuanto Eva mexicana, Judit fracasada o el doble opuesto de la Virgen de Guadalupe. Por medio de abundantes referencias y emulaciones provenientes de Josué, la obra teatral en cambio establece una anagnórisis de doña Marina en Rajab. Mediante tal afinidad se reestructura la tradición mítica, literaria y exegética, o al menos se la cuestiona, y la contemporaneidad permanece.

Uno de los mecanuscritos autógrafos de la obra teatral, escrito en francés, da un título con tachaduras: "L'Apprenti [sic] Sorcière [tachado Un Prologue, trois actes, cinque tableaux" (Plá Cortés 2014, p. 7). Y aunque esta primera impresión así no lo sugiera, La aprendiz de bruja es más que

15 Basta una nota al pie para el repertorio literario de Rajab. Así lo explica Dorothee Sölle: "In the Middle Ages and up to the beginning of the eighteenth-century Rahab is seldom mentioned in literature" (1994, p. 112). Sölle ofrece luego en pp. 112-113 una lista de las obras literarias, muy poco conocidas, de los siglos XIX y xx, en las que aparece Rajab: la obra de teatro en verso Rahab (1898), del alemán Rudolf von Gottschall; una de las baladas en Judah de Börries von Münchhausen (1874-1945); la novela The scarlet cord (1956), del estadounidense Frank G. Slaughter; la obra de teatro en verso Jericho (1923), en hebreo moderno, de Matityahu Shoham; y la novela Jericho (1966), en yiddish, de Shmuel Izban. Sin embargo, Sölle pasa por alto dos instancias de la literatura anglosajona: el profesor universitario estadounidense Richard Eugene Burton y William Blake. Del primero es Rahab: A drama (1906), que narra los acontecimientos previos a la caída de Jericó. Para el caso de Rajab en Blake, véase Rosso (2016), quien arguye que la canaanita es figura central en su obra. Rajab, explica el estudioso, aparece en tres profecías épicas: Milton, a poem, Jerusalem, the emanation of the giant Albion y Vala, or the four zoas, como una "powerful and largely malignant figure" (Rosso 2012, p. 25). William Blake hace muy pocas apariciones en la obra de Carpentier, y siempre en cuanto artista plástico, pues nuestro autor se atiene solamente a un "Adán de William Blake" (apud VÁsQuez 2003, p. 172), del que probablemente supo por medio de Lo barroco (1935), de Eugenio d'Ors (apud Cáceres Valderrama 1982, p. 22). 
un pastiche y más que una relectura ficcionalizada del relato que hicieron los historiadores castellanos sobre la conquista de México. El toque de Romanticismo alemán de la obra, provisto por la balada goethiana "Der Zauberlehrling" ("El aprendiz de brujo") (Goethe 1924, 1957 y 1997-2019), queda también en segundo plano, así como el poema sinfónico de Paul Dukas, L'apprenti sorcier, que Carpentier seguramente conoció. Esto se vuelve evidente en la variante autoral del título, que demuestra cierta dubitación y abre posibilidades interpretativas diversas. Ante todo, hace de "Der Zauberlehrling" sólo otra referencia literaria más, que, como se verá, goza de menos protagonismo que la historia de México, la Commedia y el libro de Josué. Pero el tema central de la balada goethiana - la incapacidad de dominar el misterioso y nunca del todo confiable poder de las palabras- permanece en el centro de La aprendiz de bruja.

Cuando Carpentier escribe que su obra teatral "es una actualización del mito del Aprendiz de Brujo" y que "plantea uno de los dramas fundamentales de nuestra época: el drama del comprometimiento" (apud Báez-Jorge 1988, pp. 102-103), las referencias textuales específicas se abstraen y se universaliza el relato. Al hablar de mito, abstrae una historia germánica — que es también griega, con el El mentiroso o el incrédulo de Luciano de Samosata-, la hace aplicable a circunstancias diversas y permite que converja con otros personajes análogos. $\mathrm{Al}$ mismo tiempo, esta equiparación permite que los mitos hispánicos y americanos, esenciales en el drama, se universalicen, bajo la luz del escepticismo y de la controversia dialógica. En parte por ser considerada "obra menor", La aprendiz de bruja opera desde los márgenes, y su inusual reescritura dantesca, bíblica e histórica la hermana con discusiones actuales.

Las fuentes textuales accesibles de La aprendiz de bruja en parte se han desempeñado como escolios de un texto inalcanzable y en parte imitan la historia textual de Malintzin y Rajab, a quienes no conocemos directamente, sino sólo por medio de lo que otros han hablado, escrito y traducido. En 1956, mientras vivía en Caracas, Carpentier escribió La aprendiz de bruja en francés para el actor Jean-Louis Barrault, amigo y colaborador suyo desde los años treinta (Moulin-Civil 2012, pp. 95-97). Al resumir en su diario el año de 1956, el "más fecundo, más rico en gratas peripecias", Carpentier escribe: 
Vuelta [de los Carpentier] a Caracas a fines de enero (el 26 creo) de 1956. En eso, Jean Louis Barrault... con extraordinaria alegría, me anuncia su venida a Caracas. Escribo para él, en francés, una pieza: L'apprentie sorcière que hoy (en esta incipiente primavera de 1957), no me parece mala, aunque hay mucho que retocar, teniendo en cuenta, además, algunas indicaciones de Barrault" (2013, pp. 189-190).

Los dos cuadernillos ológrafos, de 102 y 86 folios, que contienen L'apprentie sorcière reposan todavía inéditos en la Fundación Alejo Carpentier. Su texto es accesible únicamente en la traducción española incluida en las Obras completas (Carpentier 1983a) y publicada tres años después de fallecido el autor ${ }^{16}$. Pese a hablar con orgullo de ella en varias entrevistas - siempre usando el título en español- (Báez-Jorge 1988), Carpentier nunca editó L'apprentie sorcière en vida, y aún ahora no queda claro si estuvo involucrado en su traducción y edición. Sin embargo, creo que los acuerdos con Arnaldo Orfila, fundador y director de Siglo XXI Editores, para publicar la traducción de Carmen Vásquez, secretaria personal de Carpentier a finales de la década de 1970 en París, los sostuvo enteramente Lilia Carpentier, viuda de Alejo. Según la correspondencia de junio a septiembre de 1983 entre Lilia Carpentier y Arnaldo Orfila, albergada en la Fundación Alejo Carpentier, el plan antes de junio era publicar la obra teatral en edición separada. Hacia finales de junio, Lilia cambió de parecer y decidió publicarla en el cuarto tomo de las Obras completas, para contento de Orfila. Fue Lilia quien envió la traducción a Orfila, quien a su vez siguió detalladamente todas las indicaciones de Lilia para la confección de ese

${ }^{16}$ Aún hoy se echa en falta una edición (de cualquier tipo) del original francés. Además de los 188 folios ológrafos mecanuscritos, con notas manuscritas de Carpentier, todo en francés (signaturas C16B2S102a y C16B2S102b), en la Fundación Alejo Carpentier reposan otros 300 folios inéditos asociados a La aprendiz de bruja, que transmiten una versión actualizada del texto francés (C16B2S102c), la traducción española de Vásquez y notas al respecto (C16B2S102d, C16B2S102g, C16B2S103), notas escenográficas (C6B2S102e), correcciones al francés (C16B2S102f), y los paratextos de la edición de 1983 (C16B2S104a-b, C16B2S105). Agradezco a Rafael Rodríguez Beltrán su apoyo desde la Fundación Alejo Carpentier y al bibliotecario Armando Raggi Rodríguez la detallada información catalográfica sobre estos documentos que no he podido consultar personalmente a causa de la pandemia de 2020-2021. Para una síntesis de los archivos de la Fundación, véase Raggi Rodríguez y Rodríguez Beltrán 2016, y, para La aprendiz de bruja, la p. 366. 
cuarto volumen ${ }^{17}$. Sospecho que de no haber sido por aquellas dos mujeres cercanas al autor, esta elocuente Malinche de los años cincuenta, como tantas otras Malinches, también hubiera quedado silenciada. En una inversión poco común, aquí las palabras de un hombre son de alguna manera silenciadas, o al menos mediadas, por aquello que las mujeres dicen, escriben y traducen.

Pese a que fue traducida varias décadas luego de haber sido escrita, o precisamente por ello, La aprendiz de bruja ha merecido un continuo - y aún limitado- interés de la crítica. La génesis biográfica de la obra teatral, su andamiaje histórico, sus implicaciones sociológicas y algunas de las operaciones intertextuales que la constituyen han sido objeto de varios estudios (Báez-Jorge 1988; Galzio 1999; Garí Barceló 2015; Moulin-Civil 2012; Navarro Salazar 2006; Plá Cortés 2014; Vázquez 1986; Volek 1996). Leída usualmente como extrañeza genérica y lingüística, a mi parecer esta obra demuestra la amplitud creativa del autor cubano y su contemporaneidad, pues contribuye a debates actuales sobre la Malinche desde perspectivas insospechadas. Además, sugiere que la literatura puede difuminar tipologías binarias e imaginar formas más fluidas de representación. Gracias a la perspectiva sub specie aeternitatis bajo la cual se rige la obra teatral (y algunas novelas de Carpentier), sus asociaciones míticas y legendarias atraviesan distancias geográficas, temporales, lingüísticas y genéricas, y permiten las reescrituras que estamos averiguando ${ }^{18}$.

A causa de las indicaciones explícitas de un autor dado a juegos literarios esotéricos y numerológicos, se han pasado por alto alusiones escondidas a simple vista, como la que propongo aquí, y que permiten una lectura más completa ${ }^{19}$. La erudición

17 Agradezco a Armando Raggi Rodríguez la transcripción de la correspondencia entre Arnaldo Orfila y Lilia Carpentier. Pocas noticias he podido conseguir de Siglo XXI Editores, y las debo a Olga Ramos, Elena Bazán y Adolfo Castañón. No he podido consultar el volumen de correspondencia entre Orfila y Alejo Carpentier que, sin embargo, no incluye las cartas con Lilia, esenciales para la historia editorial de la obra carpenteriana.

${ }^{18}$ La incorporación conceptual de la eternidad en la prosa latinoamericana proviene de la propuesta teórica de GonzÁlez-PÉrez (2018) que, a mi parecer, está en línea con las teorías análogas de Eliot, Borges y Agamben antes mencionadas.

${ }^{19}$ El Carpentier esotérico y numerológico ha sido estudiado ampliamente. BEnítez Rojo (1983) trata minuciosamente la cuestión y GonzÁlez ECHEVARRía (2012) se ocupa de todo el corpus. 
carpenteriana y su habilidad para hacer confluir la summa de occidente en sus escritos — asimilando otras culturas, como las africanas y las amerindias- suponen una instancia privilegiada para el análisis comparativo. Aunque sorprendida por el escepticismo - que se vuelve desembarazo- con que Carpentier utiliza la Commedia, la crítica literaria ha dejado claro que el vínculo de Carpentier con las civilizaciones itálicas — y con Dante- es identificable en múltiples dimensiones de su obra. La progresión cronológica sucede en dirección ascendente; comienza con leves referencias, continúa con reescrituras de episodios dantescos y termina en superestructuras tomadas de la Commedia y aplicadas a novelas y cuentos ${ }^{20}$.

Se comienza a registrar la huella italiana en los escritos carpenterianos, sobre todo en la década de 1950, durante la cual se escribe La aprendiz de bruja. Exigente antologador, Carpentier prefiere personajes en los que confluyan significación histórica e incertidumbre documental. Prefiere famosos, pero con secretos; figuras cuya relevancia las coloque en el centro de la cultura, pero que, a la vez, carguen con sectores ignorados. Así, la entrada de la casi desconocida Rajab en el castillo carpenteriano de ilustres personajes parece extraña. Además de que sólo los tratadistas bíblicos la mencionan, pocas y olvidadas iluminaciones medievales llevan la efigie de Rajab, y ninguno de los maestros pintores de la historia le ha dado el puesto que tienen otras mujeres bíblicas marcadas por la traición, como Judit $^{21}$. Pero en La aprendiz de bruja lo que se ve es una improbable Rajab a la italiana.

Antes de la Divina commedia, Rajab era territorio intransferible (y muy frecuentado) de la literatura exegética, primero hebraica, como modelo de conversión, y luego patrística, en cuanto "bisabuela" de Cristo y tipo teológico de la Iglesia en el que todos los pecadores encuentran la redención. Era poco útil para fines literarios. Es Dante quien inserta a esa Rajab rabínica y patrística en la poesía occidental, aunque transformada

${ }^{20}$ Para una descripción pormenorizada del proceso, véanse los estudios de Navarro Salazar (2006) y de González Echevarría (2012).

${ }^{21}$ De entre las representaciones plásticas de Rajab que SöLle (1994, pp. 104-113) refiere, abundan manuscritos iluminados y mosaicos medievales. Sólo un grabado de Doré (p. 113) y una pintura de Chagall (p. 105) son indicativos de intereses menos didácticos. Por lo demás, hay grabados renacentistas de Rajab, sobre todo de holandeses como Harmen Jansz Muller y Pieter Jalhea Furnius. 
en una suerte de neologismo olvidado, como otros tantos que el poeta creó. La vuelve material artístico contemporáneo y no sólo objeto religioso. Dante, que representa a Rajab en una escena apoteósica en el canto noveno de su Paradiso, infunde nueva vida literaria al personaje y así lo rehabilita a ojos de Carpentier. Éste seguramente llegó a la Commedia por medio de José Lezama Lima, pero pudo haber sido también por medio de Borges, a quien Carpentier había leído muy bien hacia 1940 (Rodríguez Monegal 1982; González Echevarría 2012, p. S217; Mazzotta 2004). Por lo demás, el autor de La aprendiz de bruja probablemente leyó la Commedia en el italiano original con la ayuda del traductor-presidente Bartolomé Mitre en su muy reeditada traducción.

Pasados injustamente por alto, los resúmenes que Mitre confeccionó para cada canto pueden ser más importantes en estos asuntos que el mismo texto traducido. Se sabe que Mitre no dejó de corregir y editar su traducción hasta llegar a la versión definitiva de 1897. Seguramente todas esas reediciones condicionaron a los lectores hispanohablantes de la Commedia. De hecho, el resumen del canto noveno del Paradiso que ofrece Mitre me hace pensar que ése fue el umbral por el que Carpentier descubrió a Rajab y a Dante por primera vez. Esto sería indicativo de una transferencia "horizontal", sur-sur. Apunta, pues, a una configuración independiente del repertorio dantesco en América Latina, y merecería más atención de la que se le ha dado. Además, al valerse de resúmenes y compendios para sus fuentes iniciales de erudición, Carpentier imita una usual práctica de los dramaturgos, como Calderón o Lope ${ }^{22}$.

...la meretriz Roab; avaricia de los eclesiásticos... El trovador Fulqueto de Marsella, poseído de un grande amor como el Dante, le muestra el alma de la cortesana de Jericó, que salvó a los judíos en la conquista de la tierra prometida. Este gran recuerdo se ha borrado del espíritu de los que estudian las falsas Decretales, como fuentes de riqueza mal habidas y abandonan el Evangelio y los doctores de la iglesia, que sólo prometen felicidades celestes (Alighieri 1922, p. 453).

${ }^{22}$ Kallendorf (2007, p. 23) señala el uso de compendios casuísticos en Calderón. Sobre Fuente Ovejuna dice López Estrada (1969, p. 19) que "Lope no sintió escrúpulos de erudito historiador" al valerse de la Chrónica de Rades como fuente principal. Véase también el clásico estudio de JamEson (1937). 
En ese breve párrafo introductorio y en el título temático que lo antecede, Mitre resalta características que, como se verá, serán muy a propósito de las intenciones poéticas y retóricas de $L a$ aprendiz de bruja, como el amor, el robo, la codicia y, en particular, la conquista.

Las afinidades entre la doña Marina de La aprendiz de bruja, la Rajab bíblica y aquella dantesca ofrecen razones suficientes para defender que Carpentier se sirvió de estas dos fuentes de la mujer de Jericó para crear su propia versión. Rajab es, por lo demás, un personaje muy adecuado para los fines retóricos e ilustrativos del drama. En la abigarrada multitud de fuentes cronísticas, históricas, mitológicas y literarias que fundamentan la pieza, la imitación del Antiguo Testamento y del poema dantesco trascienden a una emulación creativa. Catalizador de intercambios culturales (como Malintzin), Dante tendió el puente entre el texto bíblico y su aplicabilidad simbólica en nuevos contextos; en este caso, el de la historia mexicana.

La más amplia confirmación de afinidad textual dantesca se encuentra en el calendario simbólico de ambas obras. Mientras Alejo Carpentier en 1956 escribía La aprendiz de bruja, también publicaba una novela corta, El acoso, que, como el viaje de Dante, inicia en los albores del Viernes Santo y termina el Domingo de Pascua (González Echevarría 2012). La aprendiz de bruja repite el mismo tiempo diegético. En la pieza teatral, el Viernes Santo rige el "Prólogo" que representa la llegada de Hernán Cortés a Mesoamérica (pp. 31-42). Carpentier se asegura de que el inicio de la acción dramática coincida con el inicio de la conquista y, además, con la cronología dantesca. El sintético "Prólogo" de la obra teatral representa episodios que históricamente ocurrieron durante varios meses - según lo refiere Bernal Díaz del Castillo (2011, pp. 136-137) - , pero que en el escenario giran alrededor del Viernes Santo del desembarco. Además, las didascalias describen en estas escenas un ritual exacto al de la Liturgia de la Pasión, propia del Viernes Santo. Primero ha de verse una cruz, "alumbrada desde el fondo, [que] se yergue lentamente" (p. 40). Más adelante, otra didascalia describe que los personajes centrales, conmemorando la crucifixión de Cristo, "se arrodillan al pie de la Cruz" (p. 41). El telón de la obra, y también el de la historia de la conquista, se levantan el mismo Viernes Santo que rige la acción escénica prologal.

Como conviene al simbolismo dantesco, la obra se cierra un Domingo de Pascua. Después de que Marina pronuncia su 
última palabra, se lee "Telón" y, en la siguiente línea, una fecha, comentada: "2 de abril, Domingo de Resurrección, de 1956" (p. 143) ${ }^{23}$. Esta fecha, sin embargo, no existe, porque en 1956 el Domingo de Resurrección cayó el $1^{\circ}$ de abril. Pero importa poco si Carpentier realmente terminó de escribir esta obra ese día o si se trata de un error de imprenta. Lo que importa es cuándo concluye la obra. Al añadir la festividad religiosa, el día normal adquiere una potencialidad iterativa, ritualística, propia del teatro. La fecha que pretende ser índice de la realidad es ahora parte de un mundo dramatizado con coherencia interna. A semejanza de la Commedia, el tiempo simbólico de La aprendiz de bruja se enmarca entre el Viernes Santo y el Domingo de Pascua. Se trata de un llamado de atención sobre el código interpretativo de esta obra, cuya negociación con la Commedia termina abriendo puertas para diluir los significados cerrados sobre Malintzin.

Podría objetarse que, en la intensidad de la reescritura, Carpentier extravía sus fuentes. A diferencia de, digamos, las modernas letras anglosajonas, donde el influjo dantesco ha sido más sistemático, canónico y sostenido (Ellis 1983; Paolucci 2004; Praz 1966), en las reinterpretaciones carpenterianas, como Navarro Salazar (2006) lo ha explicado para El arpa y la sombra, "il testo [dantesco] perde lo spessore ideologico e diventa una citazione, quasi a sfoggio culturale" (p. 211). Las reescrituras dantescas de Carpentier operan por medio de una visión doble, a la vez erudita y heterodoxa, mediadas por la lectura de otros latinoamericanos, sean Mitre o Lezama.

En el caso de La aprendiz de bruja, la divergencia más grande con respecto a Dante pertenece a las características elocutivas de ambas protagonistas. Rajab "scintilla / come raggio di sole in acqua mera" (Paradiso, IX, w. 113-114) 24, "nel sommo grado si sigilla” (v. 117). Además, después de la Redención, Rajab fue la primera persona precristiana en ascender (Robinson 2009, p. 258): "pria ch'altr' alma / del trïunfo di Cristo fu assunta" (vv. 119-120). En este tercer cielo de Venus donde estamos, Rajab brilla más que ninguna otra alma, y su figura se representa ensalzada, tal como Petrocchi lo determina (Ali-

23 Françoise Moulin-Civil (2012) ha notado solamente el Domingo de Pascua, quizás como el fin de una "pasión" "propre à tout acte d'écriture et donc propice à une manifestation de soulagement" (p. 99).

${ }^{24}$ Cito la Commedia en italiano por la edición de Giorgio Petrocchi (AliGHIERI 1966-1967) y la de Enrico Malato (Alighieri 2018). 
ghieri 1966-1967, p. 151, nota). Rajab constituye el centro simbólico y visual del ámbito que ocupa. Sin embargo, el primer atributo que la marca es la tranquilidad: "là entro si tranquilla / Raab" (vv. 115-116). Traducida en absoluta beatitud, su apoteosis implica silencio. Rajab no pronuncia una sola palabra en Paradiso, y quien recuenta su historia es un hombre, el trovador Folquet de Marselha. Después de todo, Rajab alcanzó la salvación precisamente porque dosificó su silencio. Calló ante su pueblo la presencia del invasor extranjero. Su discurso más eficaz, con los espías de Josué, la salvó de la muerte y se selló con un signo visual, no con la palabra (Josué 2:8-21). Hablo del conocido funiculus coccineus, el "cordón de grana" que ató a su ventana para significar que aquella, su morada, no debería ser destruida. Como Malintzin ante los mexicas, Rajab administra sus palabras en función de las necesidades del conquistador. Pero mientras Rajab dosifica silencios, Malintzin dosifica alocuciones; traducciones, de hecho.

Intérprete de Cortés, Malintzin aparece en los relatos y códices mexicanos de la época con el hálito de la voz y la mano gesticuladora, todos índices de elocuencia y acción. De ahí que Chimalpahin (1579-1660), el gran historiador nahua, explicara que el epíteto "Tenepal" formaba parte del nombre propio de Malintzin, una referencia a sus capacidades lingüísticas (Chimalpahin's conquest... 2010, p. 32; Townsend 2006, p. 76). Durante los primeros años de la década de 1520, la cadena de comunicación entre españoles y mexicas comenzaba con Cortés, quien hablaba castellano. Luego pasaba por Jerónimo de Aguilar, quien hablaba castellano y maya; después por Malintzin, quien hablaba maya y náhuatl, y concluía en interlocutores como Moctezuma o sus emisarios. Tanto poder tenía la palabra y el nombre de la nahuahablante que los pueblos y los jefes mexicas solían llamar al conquistador de México no por su nombre cristiano, sino por el nombre de su intérprete: "Malinche", y no Hernán Cortés — de donde, entre otras cosas, la "Capitán Malinche" de Glantz 2003.

Este punto divergente entre Carpentier y Dante - la elocuencia de Marina y el silencio de Rajab- no distancia su relación, sino que la estrecha. Los tratadistas dirían que estamos ante el tipo de reescritura que trasciende la pacífica similaridad de la imitatio hacia la polémica superación de la aemulatio (Pigman 1980). Al otorgar voz y protagonismo a Marina, y no un puesto central pero mudo o secundario como el de 
Rajab, Carpentier comienza su propia hermenéutica dantesca y bíblica. Al personaje de Cortés, en efecto, le dice Marina en La aprendiz de bruja, durante la matanza de Cholula: "El destino de vuestro Imperio parece depender de la más ínfima de mis palabras" (p. 73). Habrá de notarse aquí, además, la habilidad de Carpentier para imbricar referentes literarios y refundirlos. En aquel diálogo de Marina parecen resonar ciertos versos de "Der Zauberlehrling" que hablan sobre el potencial poder de una palabra para restituir el cosmos, simbolizado en la escoba encantada: "iHe olvidado la palabra! / La palabra, ¡ay!, merced a la cual tornará la escoba a ser al fin lo que ha sido" (Goethe 1924).

Los parlamentos que el personaje de Marina dice después de la histórica y complejísima matanza de Cholula y que relaciona el Imperio español con la ínfima palabra, nos llevan a pensar en los territorios geográficos y su administración. Aunque en la segunda escena del primer acto Carpentier, por boca de Cortés, compare Cholula con la Torre de Babel, el modelo subyacente de la ciudad mexica en la obra teatral es otro sitio bíblico, Jericó. Al haber sido una de las ciudades más sagradas de los mexicas, para los cristianos destruir Cholula significaría — simplificando los asuntos doctrinales- una extirpación de idolatrías, una ofrenda sacrificial. Paralelamente, la destrucción total de Jericó se convierte en un herem de exterminio, en un "anathema Domino", 'ofrenda sagrada al Señor' (Iosue 1995, 6:17; Fernández 1924, p. 25). Jericó y Cholula son dos ciudades que, por haber sido destruidas, se acercan a la divinidad invasora ${ }^{25}$. Por si esto fuera poco, apenas comenzada la acción dramática, nuestro Cortés ficcionalizado se define a sí mismo como un nuevo Josué. "Prefiero el papel de Josué. Es más fácil de soportar" (p. 51), dice, y niega el otro personaje del que él mismo habla, Prometeo. Cuando niega este mito como modelo - que es reminiscente del brujo de Goethe y también de otro poema goethiano, "Prometheus"-, la negociación entre fuentes literarias se inclina nuevamente a favor del modelo hebraico.

La función providencial del líder guerrero que santifica la destrucción y avala su brutalidad también ocurre en ambas historias. La Rajab bíblica reconoce que los hijos de Israel, en la persona de Josué, tienen poderes divinos: así lo demuestran

${ }^{25}$ Otro relato bíblico que se ajusta a esta narrativa es la de Sodoma y Lot, el sobrino de Abraham. 
la apertura del Mar Rojo, la destrucción de los reyes de los Amorrheos, de Sehón y de Og. Rajab reconoce además que Jericó es tierra divinamente entregada a los conquistadores (Josué 2:913). La Marina carpenteriana, representada con similar erudición, comienza pensando que el poder de los recién llegados es sobrenatural y que la divinidad los guía. “No habéis sido guiados hasta aquí por una Columna de Llamas, como el pueblo judío en el desierto?" (p. 55), le pregunta a Cortés en la obra teatral, bastante después del desembarco. Cuando éste responde afirmativamente, Marina regresa a un pasaje del "Prólogo" de la obra, reminiscente además de los presagios de la venida de los españoles, según lo cuentan los relatos autóctonos ${ }^{26}$ : "Yo la vi [la Columna de Llamas]" (loc. cit.). El personaje de Gonzalo de Sandoval, conquistador subordinado a Cortés, asegura de doña Marina: "Piensa que somos seres sobrenaturales" (p. 50). Además, Cortés mismo sostiene que haber encontrado a Marina es razón suficiente como para no dudar de que "el Señor le ha hecho [a él] un instrumento de su voluntad" (p. 52). Rajab, escribe Dante, "favorò la prima gloria / di Iosüè in su la Terra Santa" (Paradiso, IX, wv. 124-125). Y aunque Carpentier reproduzca el error de creer que todos los pueblos amerindios tomaron a los europeos como dioses, permite también vislumbrar la construcción superpuesta de este Cortés de ficción ${ }^{27}$. En suma, la destrucción de la ciudad (Jericó-Cholula) crea un espacio sagrado (lo anatematiza, o es un herem de exterminio, para usar tecnicismos doctrinales), y el líder violento (Josué-Cortés) se erige como líder sacrificial. En La aprendiz de bruja, sin embargo, los valores positivos que la interpretación bíblica y cierta parte de la historia han otorgado a estos eventos sufren transformaciones críticas. En función de quién lo mire y cuándo, Josué y Cortés son héroes o saqueadores.

Ambos líderes, Josué y Cortés, además de mostrar un interés religioso, también muestran otro, de orden económico. Anticipando el estereotipo del conquistador español, dice Josué

${ }^{26}$ Para ciertos presagios de los relatos de herencia precolombina, véase el primer capítulo de la esencial obra editada por Miguel León-Portilla, Visión de los vencidos (1961, pp. 1-11).

27 Más adelante, el "Hombre del espejo" dirá que se equivocó al haber anunciado el regreso de Quetzalcóatl: "Pero no regresó. Será otra vez" (p. 135). La idea errónea de que los naturales mexicanos percibieron a los europeos como dioses ha sido analizada con detalle y erudición por TownSEND (2003; véase también 2006, pp. 45-54). 
(6:19), en la traducción de Cassiodoro de Reyna de 1569: "Mas todo el oro y plata, y vasos de metal y de hierro sea consagrado a Jehová, y venga al thesoro de Jehová" ("repositum in thesauris ejus", dice la Vulgata). Pero esto, en el sistema de valores del libro bíblico, no es avaricia ni es saqueo; es un anatema, una repositio, un devolver a su sitio legítimo. La sagrada escritura, muy convenientemente, ofrece la historia contrastante de un avaro verdadero, Acán (mencionado también en Purgatorio, XX, v. 109), un israelita que acompaña a Josué. Acán roba, pero no a Jericó directamente, sino el tesoro obtenido en Jericó a nombre de la divinidad. Roba, en otras palabras, a sus hermanos israelitas ${ }^{28}$. Cortés no sigue los pasos de Acán; sigue los de Josué, porque, tributando las riquezas americanas al sacro emperador romano Carlos V, las entrega, simbólicamente, a Dios. Hizo, como diría Juan Ginés de Sepúlveda, guerra justa (justum bellum), y repone el tesoro de Dios. Sin embargo, Carpentier, a lo mejor esperando lectores versados en las Sagradas Escrituras, omite la mención de este detalle en las citas bíblicas que el personaje de fray Bartolomé de Olmedo lee a Marina. Este detalle de avaricia sagrada completa a la perfección la relación especular entre ambas historias.

En esto Carpentier parece seguir a Dante, quien también obvia la avaricia sagrada de Josué y, en cambio, la traduce en crítica de la avaricia pecaminosa de los eclesiásticos: "l'Evangelio e i dottor magni / son derelitti, e solo ai Decretali / si studia, sì che pare a' lor vivagni" (Paradiso, IX, vv. 133-135). En lugar de estudiar los escritos de los padres de la Iglesia o historias ejemplares como la de Rajab, los eclesiásticos que Dante critica se afanan estudiando derecho canónico, porque ello supone ganancia económica; Charles S. Singleton explica así este pasaje ${ }^{29}$. Tanto para Dante, por medio de Folquet de Marselha, como para la pieza teatral, mediante el fraile mercedario Olmedo, el libro de Josué sirve de punto de referencia de una ideal conquista desinteresada. El componente de avaricia se desplaza a otros personajes y queda latente en la referencia tácita al texto. En la Commedia, quienes reciben el estigma de la codicia son el papa, los cardenales y los florentinos; en La aprendiz de bruja, son ciertos espa-

${ }^{28}$ La diferencia de la aplicación del herem a Acán y a Rajab es discutida por Jackson (2012, pp. 89-92).

${ }^{29}$ Comentario a Paradiso, IX, vv. 133-135, de Charles S. Singleton, citado por el Dartmouth Dante Project. 
ñoles quienes reciben el estigma de la codicia, gracias a la visión de un personaje mexica.

En la segunda escena del primer acto, una "Dama de alta condición" dice a Marina que a los españoles, "al principio, se les tomó por dioses". Pero luego asegura: "iSon unos puercos...! Con esa codicia de oro y de todo lo que brilla" (p. 68) ${ }^{30}$. De igual manera Dante, en voz de Folquet, se queja de que el florín de oro producido en Florencia, ese "maledetto fiore" (Paradiso, IX, v. 130), haya corrompido a la curia y los haya animalizado, "fatto ha lupo del pastore" (Paradiso, IX, v. 132). Y aquí se ve, por último, la mano del traductor-presidente Mitre de nuevo, porque en el título temático del canto noveno del Paradiso pone "avaricia de los eclesiásticos" (Alighieri 1922, p. 453). Se tiene, pues, afinidad temática y, además, encadenamiento y sucesión paralela de los temas: el sacrificio de una ciudad, la providencialidad del líder guerrero y la crítica de sus intereses económicos.

En torno a los personajes de ciertas novelas de Carpentier, se han indicado componentes alegóricos, análogos a los de la Commedia. Hay personajes específicos, como don Marcial, marqués de Capellanías en "Viaje a la semilla", Juan en "El camino de Santiago" o el potentado mexicano de Concierto barroco, que esconden, detrás de su construcción literal, un sistema de significados desplegado en paralelo a la ficción, y que indican otra realidad, externa y extensa, que llega incluso a representar a todo el género humano. En La aprendiz de bruja la alegorización, como podría suponerse de una pieza dramática, ocurre de continuo y recuerda, además, al teatro renacentista y medieval. Cortés podría ser alegoría del ímpetu conquistador del imperio ibérico, que aspira a maniobrar el orbe. Fray Bartolomé de Olmedo alegoriza las pretensiones teológicas de la Iglesia en el Nuevo Mundo, sobre todo por medio de la predicación oral. Los personajes mexicas representan el pasado americano destinado al olvido o a la transmutación; y, Marina, el proceso inacabado, inacabable y paradójico de la construcción - o fundación- de un nuevo mundo.

El intrincado frontispicio de una de las primeras ediciones de la Historia verdadera de la conquista de la Nueva España

30 Esto también hace eco de los códices antiguos. Cuando los españoles reciben los regalos que envía Moctezuma luego de la matanza de Cholula, cerca de Popocatépetl, se lee en el Códice florentino: "Como unos puercos hambrientos ansían el oro". León-Portilla indica en nota que "el texto náhuatl dice pitzome, 'puercos de la tierra'” (2011 [cap. 6], p. 53). 
(1632) de Bernal Díaz del Castillo (Imagen 1) también está organizado por medio de alegorías. Se sabe que el texto de Bernal ha marcado la literatura de Carpentier y de América Latina, pero los elementos visuales de las "crónicas de Indias", como este grabado, han sido también muy trascendentes (recuérdense, por ejemplo, las ilustraciones de Gonzalo Fernández de Oviedo). Es posible que la admiración hacia Bernal Díaz haya llevado a Carpentier a consultar algún ejemplar original del libro en Madrid o París, pues lo consideró "el primer clásico de la literatura hispanoamericana" (Carpentier 1970, p. 24). Sin embargo, me parece más probable que Carpentier saciara su curiosidad en uno de esos manuales de bibliófilos tan comunes en la primera mitad del siglo xx, que ofrecían abundantes reproducciones de las portadas ${ }^{31}$.

La portada que figua en la Imagen 1 es sin duda un registro histórico de su época. Sin embargo, el frontispicio es también un arco triunfal, y una alegoría por excelencia preside el conjunto: el escudo de armas del monarca español. Éste, junto con el de Cortés, está en lugar de instituciones o linajes. Así también las dos figuras humanas de Cortés y Olmedo, las figuras cartográficas del hemisferio y de la ciudad, y las sucintas palabras latinas, todos ellos representan mucho más de lo que vemos. Lo propio acontece en La aprendiz de bruja, pero con un giro moderno. Carpentier cita a Díaz del Castillo, pero transformando el material fundamental por medio de un mecanismo dantesco "alegorizador", semejante al del teatro alto moderno o al del frontispicio de la Historia verdadera. Mientras que Díaz del Castillo y el Antiguo Testamento pretenden presentar personajes históricos en sus textos, Carpentier, emulando a Dante, amplifica la especificidad personal y la ubica más allá de sus contingencias históricas.

Pero también el espacio se vuelve alegórico. Al menos aquel ocupado por Marina y Rajab. En Carpentier y Dante, ambas mujeres comparten la misma alegoría espacial, que es a la vez marcial y venérea. Un solo gesto bastó para cambiar la historia de sus imperios putativos. Un gesto, además, de raigambre erótica. Peter Hawkins (2009) explica que en el tercer cielo, donde

${ }^{31}$ El de Vindel (1930, p. 50) incluye el facsímil del frontispicio en cuestión y, además, la Biblioteca Nacional de Venezuela cuenta con los 12 tomos que lo componen. Es admisible imaginar a Carpentier consultándolo en Caracas. 


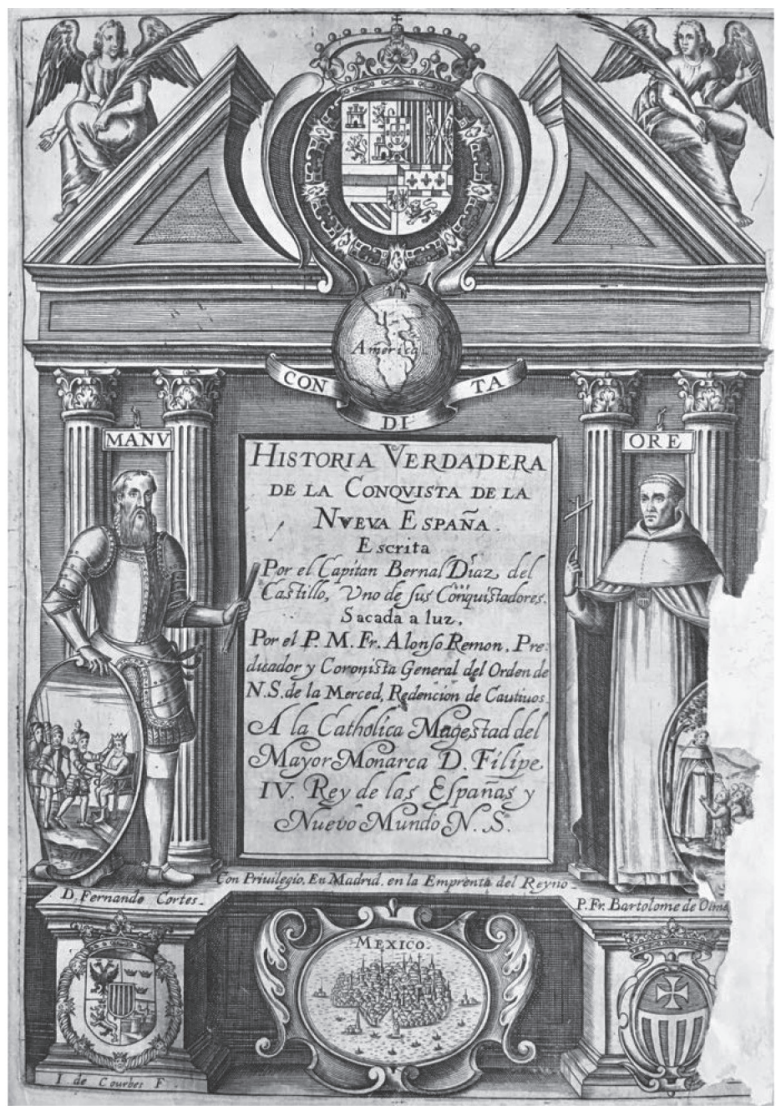

IMAGEN 1. Frontispicio de la "Historia verdadera de la conquista de la Nueva España” (1632) de Bernal Díaz del Castillo (Cortesía de The Beinecke Rare Book E Manuscript Library, Yale University).

estamos, Dante "in essence... bring[s] together Mars and Venus. He celebrates the theme of conquest on many counts" (p. S78). Por una parte, Dante solicita más cruzadas. Por otra, se empeña en acercar el tercer cielo (erótico) de Venus al amor verdadero de Dios, que mueve el sol y las estrellas del cuarto cielo. Dante se sirve de Rajab, pese a que Beatriz sea la figura central en este empeño $(i d$.$) .$

El primer acto de La aprendiz coincide en esto, cuando una Marina azorada responde a Cortés: "Te amo. Lo que es peor. Nunca he caído tan bajo, ni cuando los mercaderes de esclavos mostraban mis senos, mi vientre, a los compradores" (p. 75). A este tercer cielo de Venus, Dante no lo desprovee de la sombra 
del mundo ni de polémicas de corte político; también las palabras de doña Marina están aquí impregnadas de significados de esa índole. Cuando Cortés, ya casado, envía a Marina a Oluta, ésta le reprocha: “¿Cambio de dueño? ¿Eres tú el nuevo mercader de esclavos...?” (p. 119). En tal espacio alegorizado, ciertas contingencias históricas se diluyen, como el hecho de que Carpentier represente a Marina sin hijos, cuestión que, como dije, ha desconcertado a la crítica. Esta ausencia de progenie estrecha ulteriormente el vínculo con Rajab, de cuyo papel como madre nada dice el libro de Josué. Pero sobre todo subraya un camino divergente a las interpretaciones binarias de Malintzin. $\mathrm{Al}$ no ser madre, el vínculo entre amor y guerra queda establecido en otra relación paralela: la figura del peregrino.

Doña Marina en La aprendiz está en un peregrinaje hacia la redención, ya sea como autoconciencia o como crítica del comprometimiento. Este movimiento ascendente recuerda a Dante-pellegrino y a las almas del purgatorio. También peregrinan los conquistadores, en diferentes momentos de la obra teatral, ya que todos buscan solventar los problemas que suscitaron las complejas transacciones allende el Atlántico. Marina es bautizada en el "Prólogo", con lo cual la obra aparentemente inicia no con una pagana a quien las puertas del cielo se le cerrarán, sino con una mujer conversa de nombre cristiano. Nunca la llama Carpentier con sus otros nombres, Malinalli o Malintzin o Malinche; la llama solamente "Marina" y casi siempre "doña". Insiste, pues, en su compromiso inicial como cristiana; e insiste también en un peregrinaje ascendente y ordenado que comienza canónicamente en el Infierno, pero que terminará en la adquisición de conciencia crítica. En una de las primeras veces que el personaje de Cortés se dirige a Marina, éste dice, enfático, "estamos en el Reino del Demonio" (p. 54).

Más adelante, Cortés dulcifica su discurso y dice a los soldados: "Mi deber es plantar cruces. Cruces por todas partes... Ignoro si a espaldas mías [los mexicas] arrancan las cruces que yo planto. Gracias a ellas, rotas o no, pisoteadas o no, sois algo más que unos aventureros... ¡Combatientes...! Si no captáis la sutileza, peor para vosotros" (p. 64). Y Marina misma expresa su condición de peregrina, de extranjera alienada en su propia tierra. "Soy la única en errar por dondequiera, sin nunca poder descansar en ninguna parte"; o "«Merodear» —otra palabra nueva que aprendo-. Ahora que no sirvo para nada, «merodeo» por todas partes" (pp. 117 y 123). De una forma u otra, 
en todos los personajes - y sobre todo en Marina- se expresa el concepto medieval y cristiano del Homo viator, el ser humano como viajero, como peregrino entre dos mundos, entre la alienación y el orden ${ }^{32}$. Esta Marina teatral soporta la contradicción entre ambos mundos, como la mestiza de Anzaldúa, que "turns the ambivalence into something else" (1987, p. 79). Y permanece una tensión que enriquece las otras simbologías.

Peregrinaje hacia la redención, el caminar de Cortés y sus compañeros, y de Marina también, se dirige hacia un opus restaurationis de directa analogía con Dante, como la llama Giuseppe Mazzotta (1979). En el tercer y último acto ya, los conquistadores-evangelizadores de La aprendiz de bruja tañen una campana recién forjada y de gran significación simbólica. Sandoval, el conquistador, exclama con alborozo: "Los herreros... al fin lograron hacerme una buena campana con el bronce de las viejas lombardas" (p. 114). Este instrumento religioso está hecho con el metal de armas usadas, fundido y vuelto a forjar. El bronce de los cañones guerreros se ha transformado en pacífica campana para llamar a misa. La obra de restauración de la paz se vuelve material. Cortés ordena, no sin menor emoción: "Henos aquí de nuevo en las industrias de la paz... que le den un moyo de vino a los fundidores" (p. 115). Simbolizadas por los cañones invencibles, la violencia y la desesperación iniciales han sido literalmente diluidas en la paz de la redención prometida. La desesperanza propia del Inferno, del Reino del Demonio, ha sido reemplazada por la música celestial de un peregrinaje purificador dirigido hacia un paraíso - recuérdense los múltiples himnos que "musicalizan" el Purgatorio.

Poco más adelante en la obra teatral, el "Hombre del Espejo", que sirve de guía y profeta, y por tanto es análogo al Virgilio dantesco, instruye a Marina en una restauración espiritual distinta. La escatología mexica que el Hombre del Espejo le enseña, preñada de recuerdos dantescos, abunda también en reminiscencias de la poesía escrita por Nezahualcóyotl (14021472) ${ }^{33}$. Dice el Hombre del Espejo a la Marina escénica:

32 Para un estudio histórico-cultural completo del Homo viator, véase el fundacional artículo de LADNER (1967).

${ }_{33}$ Nezahualcóyotl fue tlatoani (es decir príncipe) y poeta de Texcoco en el siglo Xv, conocido sobre todo gracias a las obras históricas del escritor novohispano Fernando de Alva Ixtlilxóchitl ( ca. 1578-1650). 
La muerte no es nada. Es el comienzo de un viaje de cuatro días por un viento helado. Pasarás entre dos montañas, sufrirás la prueba de las fieras, atravesarás ocho desiertos, escalarás ocho colinas. Después, el viento cesará. Vendrá el silencio. Entonces pasarás a una de las nueve moradas eternas, donde se olvidan todas las cosas de este mundo... No hay juicio (p. 133).

Y Marina responde, delatando nuevamente la ambigua representación cristiana: "Todavía prefiero la esperanza de un juicio” (p. 134). La obra finaliza con Marina agonizante, quizás redimida, casi en el Paraíso. "Sin ninguna figura sobrepuesta", ella misma se describe (p. 142). Y en el mejor tono pío, durante lo que podría interpretarse como su apoteosis o su triunfo paradisíaco, alza la voz: "Heme aquí... ¡Desnuda, herida por tus clavos, sin la mentira de la forma humana!" (loc. cit.). Pese a lo que este final en clímax pueda indicar, La aprendiz de bruja no imita la liberación de Rajab. La reescribe. He hablado de lecturas y preguntas heterodoxas, críticas incluso. Y es esto, precisamente, lo que la "segunda" Rajab, es decir la Marina carpenteriana, hace: duda de su propia redención.

No es de sorprender que Carpentier se aleje del modelo dantesco y bíblico. Ni los propios exegetas bíblicos se han librado siempre de dudas con respecto a la historia de Rajab (Binik 2018). Y decir que la Malinche no suscita asociaciones unívocas es repetir lo conocido. A diferencia de la visión tradicionalista, exegética e histórica, otras interpretaciones admiten un activo perspectivismo. Según el observador, estas dos mujeres son meretrices traicioneras o fieles cortesanas. En todo caso, otros suelen hablar por ellas. La aprendiz de bruja, sin embargo, sugiere una narrativa marcada por la voz propia, consecuencia de la autobiografía (ficticia) y de la contemporaneidad como estrategia literaria que trae a Rajab a escena. Así, la obra moderniza al personaje y lo impregna de fluidez. Junto con la voz, le otorga un don renacentista y barroco, que la nueva mestiza de Anzaldúa (1987, p. 23) también estima esencial: la perspectiva.

La Rajab de La aprendiz de bruja, es decir esta Marina que lucha por un espacio discursivo, ve sus propios actos desde varios puntos de vista y dos o tres lenguas. Se sabe fiel a Cortés y, por tanto, tiene sus esperanzas puestas en la Corona de Castilla y en la divinidad cristiana que quizás la redime al final. También se sabe comprometida con su pueblo. Es instrumental en la matanza y en la ruina del Jericó mesoamericano que es Cholula y que 
representa a toda América. Pero a la vez es mucho más. Aquí es donde mejor demuestra esta pieza teatral que aun la creatividad literaria de los años cincuenta podía descreer de tipologías rígidas. Salvando diferencias generacionales y genéricas, la Malintzin de La aprendiz de bruja termina pareciéndose más al "speaking subject" que Alarcón (1989, passim) encuentra en teorías chicanas que al neomito de Paz. Es capaz de traducirse y narrarse a sí misma. Redefinida al margen de la religión organizada y de su maniqueísmo, esta Marina sobrevive pese a todo, tiene conciencia de su complejidad humana y, asombrosamente, su discurso simpatiza con "latter-day speaking female subjects" (p. 72).

Carpentier no sólo se remonta a Dante, sino que lo glosa y le responde. Conversando con el fraile mercedario Bartolomé de Olmedo, contraparte religiosa de Cortés, doña Marina intenta educarlo:

Padre, el Paraíso se ha convertido en algo muy vago, desde que los hombres fueron expulsados de él... En una época creí que los hombres que vinieron del Este habían encontrado el camino y las llaves... Pues bien, esos hombres venían a buscarlo [el Paraíso] aquí. ¡Es aquí que pensaban encontrarlo...! ¡Qué irrisorio...! (p. 139).

Si se admite que Marina es una "segunda Rajab", el hecho de que niegue que está en el Paraíso puede leerse como un cuestionamiento de Carpentier sobre la categoría apoteósica de Rajab en la Commedia. Podría decirse, incluso, que Carpentier refundió la tradición del motivo rajabiano para dotarla de ética moderna. Esta Rajab mesoamericana, provista de conciencia, perspectiva y voz, es capaz de dudar. Al mismo tiempo, Carpentier está aquí cuestionando el mito del paraíso terrenal en América. Auspiciado por tradiciones populares europeas - recuérdese la tierra de Jauja o los subtextos de la "Carta de Colón"-, el mito terminó proyectándose en una visión utópica e irrealizable del Nuevo Mundo. Tal proyección, como se sabe, desembocó en un paradójico "paraíso", administrado por medio de encomiendas, mitas y otros sistemas esclavizadores. Carpentier habría de acudir a este amplísimo asunto en otros textos, como en el cuento "El Camino de Santiago"34. En La aprendiz de bruja, devuelve el asunto paradisíaco a la Commedia.

${ }^{34}$ Las reminiscencias dantescas de este cuento se analizan en CRESPOJARAMILlo 2021.

Nueva Revista de Filología Hispánica (NRFH), LXX, 2022, núm. 1, 207-242 ISSN 0185-0121; e-ISSN 2448-6558; DOI: 10.24201/nrfh.v70i1.3788 
Carpentier no repite el motivo dantesco con ortodoxia. Introduce un sentimiento impensable bajo lógicas confesionales estrictas: empatía y hospitalidad con el infiel. "iEs intolerable!", dice Marina ante la masacre de Cholula, “¡Es como si recibiera balas en mi vientre!". Y luego, a fray Olmedo y a Cortés: "¡Pero los que matáis ahora ¡...tienen para mí un rostro diferente del que tienen para vosotros! ¿Qué sabéis de sus juegos? ¿De sus canciones? ¿De su ternura? Para vosotros son solamente adoradores del Demonio. Y hay mucho más que eso" (p. 72). Esta preeminencia de la empatía por sobre los intereses individuales podría conducirnos a pensar en una Malintzin nuevamente mitificada. Según se supone por el final providencial de la primera Rajab, bíblica y dantesca, su figura mítica está redimida. Sin embargo, la resquebrajada redención de nuestra segunda Rajab, quien duda y se desengaña, demuestra una nueva vía, tanto para Malintzin cuanto para Rajab.

Como he sostenido, La aprendiz disocia a La Malinche de la procreación maternal y del pensamiento binario. En consecuencia, desactiva la tipología Malintzin-traductora unida a la Malintzin-procreadora que determinó la fascinación repulsiva de sus representaciones tradicionales hasta bien entrado el siglo xx. No es una "Eva mexicana" —según la llamó Octavio Paz (1969 [1950], p. 78) en una écfrasis de Orozco-, ni son suyos los "hijos de la chingada". Recuerda, en cambio, reapropiaciones de pensadoras feministas y chicanas. La conocida Malinche de Carmen Tafolla (1993), tan reeditada, apostrofa a Cortés en líneas análogas: "You cried broken tears the night you saw / your destruction. / My homeland ached within me (but I saw another)" (p. 199). Pero estas restauraciones de Marina no vienen sin remordimiento y duda, que alcanzan aun a Cortés. La elocuencia de Marina resuena como las campanas hechas con el bronce de los cañones, con el recuerdo de masacres y demonios, pero junto a una futuridad que Tafolla sugiere: "But I saw our world / and your world / and another" (id.).

Durante este peregrinaje hacia una redención ambivalente, que ocurre a lo largo del tercer acto, Rajab termina de confirmarse como modelo y como explicación poética de Marina. En uno de los monólogos más conmovedores, reconociéndose en Rajab, Marina se lamenta por su alianza con Cortés, a quien impreca. También habría que leer este monólogo en el contexto histórico de la Revolución cubana y de los discursos sobre el comprometimiento. 
Seguí esta empresa con los ojos vendados. Ahora que puedo mirar a mi alrededor, sólo veo ruinas. En el lugar donde yacían los antiguos templos, construís iglesias... ¡Cómo uno se compromete...! Uno piensa que formará parte de una fraternidad que hará un mundo mejor... Y un buen día, uno se da cuenta de que nunca ha sabido para qué sirvió: que fue el juguete de unos Altos Designios cuyo alcance se ignora, cuya verdad se aclara demasiado tarde, cuando todo ha sido destruido, triturado, aplastado por su poder... Al día siguiente de haber abierto las puertas de Jericó a las gentes de Israel, Rajab despertó entre ruinas humeantes. Aprendí bien el texto con Olmedo: "destruyeron a filo de espada todo lo que había” (p. 121).

En su monólogo, Marina se presenta consciente de sus acciones, reflejando la desesperación del aprendiz goethiano, quien también acude a los "hohen Mächte" (Goethe 1997-2019, p. 218), los "Altos Designios", para intentar explicarse su tragedia. Pero a diferencia de aquel aprendiz, que recibe auxilio inmediato de su Hexenmeister, su maestro hechicero, esta aprendiz, Marina, aparece sola. Nadie la reconforta. Sardónico y cruel, Cortés es el único que le responde: "Reniéganos. Como Guerrero, el hombre de Cozumel” (p. 121). Con estas palabras, Cortés recuerda a un personaje tradicionalmente considerado el doble inverso de Malintzin: Gonzalo Guerrero ${ }^{35}$. Según la narrativa canónica, Guerrero y Malintzin traicionaron a los suyos por amor. Malintzin dejó a los mexicas por su fidelidad hacia los castellanos; Guerrero, en cambio, prefirió aliarse a los mayas que volver con sus compatriotas ibéricos. Mientras que la faceta masculina del mito doble, Guerrero, se transformó en héroe épico, sólo Malintzin ha trascendido a la historia como la gran traidora, perpetuamente sola y silenciada.

La única que acompaña hasta el final a la Marina de La aprendiz de bruja es Rajab. Y lo hace a manera de palabras guardadas en la memoria. "Al día siguiente de haber abierto las puertas de Jericó a las gentes de Israel”, cuestiona Marina a Cortés, "Rajab despertó entre ruinas humeantes". Luego de reconocerse en esa mujer bíblica, concluye: "Aprendí bien el texto" (p. 121). El aprendiz goethiano también memorizó un texto y unas prácticas. "De coro aprendíme, con todo cuidado, / sus palabras nimias y solemnes gestos" (Goethe 1957, pp. 133-135),

35 Para la complejidad de la historicidad de esta figura, que subraya al mismo tiempo su valor épico, véase Adorno 2007, pp. 220-245. 
se lee en la primera estrofa de la balada. En la actualización del mito del aprendiz de brujo, la aprendiz de Carpentier ya no repite un hechizo del Romanticismo alemán, sino las palabras que cuentan la historia bíblica y dantesca de Rajab, que sabemos es ella misma. Pero a diferencia de la balada de Goethe, en donde el maestro hechicero se impone y se diferencia del aprendiz, en la obra teatral de Carpentier Marina abre la posibilidad del altruismo por medio de la autobiografía (véanse Butler 2005 y Cavarero 2000).

Poco antes de la caída del telón, Marina termina por ver en la historia de Rajab su propia historia. Luego de que fray Olmedo le dice que ha sido "el instrumento de la Providencia. Como Rajab, la mujer de Jericó", Marina replica: "Ésa es otra que debió preguntarse, al verse entre montones de cadáveres: «¿Quién soy? ¿Cuál ha sido mi papel en este asunto tan terrible...?» Un cronista vacila ya frente a mi destino, sin poder explicárselo... ¿Viví para el Bien? ¿Viví para el Mal...?” (p. 140; cursivas añadidas). Ese cronista es Bernal Díaz del Castillo, ficcionalizado, pero su vacilación podría ser la nuestra, al reescribir el relato o ver el drama. Complicando tanto la Rajab de Josué cuanto la Rajab apoteósica de Dante, esta "segunda Rajab" que es Marina mantiene la duda sobre el peregrinaje redentor y cuestiona sus propias acciones. Pero nace en ella una profunda conciencia crítica, cifrada en el resquebrajamiento ontológico y en el gesto altruista de dar voz a Rajab. En esa pregunta que Rajab se hace por boca de Marina, Marina se está dirigiendo a sí misma, pero también a Rajab. Si por boca de Marina, Rajab se dice “¿Quién soy?”, de hecho ambas se están preguntando mutuamente: “¿Quién eres?”.

En otro texto muy posterior, Carpentier también representa una Malinche simple, típicamente maniquea. La novela Concierto barroco (1974) trata de un criollo mexicano del siglo XVIII que, en un viaje a Europa, se encuentra con Antonio Vivaldi. Interesado por la historia de México, Vivaldi compondrá Motezuma, dramma per musica -obra que en realidad existe, estrenada en 1733. En cierto momento, el protagonista de Concierto barroco se queja por una ausencia importante en el libreto (la nombra con respeto, "Doña Marina"). El Vivaldi ficticio de Carpentier le responde: "La Malinche esa fue una cabrona traidora y el público no gusta de traidoras. Ninguna cantante nuestra habría aceptado semejante papel. Para ser grande y merecedora de música y aplausos, la india esa hubiese debido hacer lo 
de Judith con Holofernes" (p. 193). En este breve parlamento, Carpentier apunta al malinchismo que uno esperaría en las relecturas del mito durante el siglo xx. Ofrece aun otra mujer bíblica como comparación negativa de Marina, la viuda hebrea Judit. Tras seducir al invasor Holofernes y decapitarlo, Judit salvó al pueblo de Betulia. Carpentier hace decir a Vivaldi que Cortés es un nuevo Holofernes y, por tanto, que la europea es una cultura de barbarie. Marina, pues, debió haber decapitado al bárbaro Cortés para que la civilización —-mexica, adviértasetriunfara. Este paralelismo resulta históricamente imposible y, por tanto, literariamente irónico. A la vez que reivindica la cultura mexica, Concierto barroco también refuerza las tipologías binarias. La Malinche ya no sólo protagoniza el pecado como "Eva mexicana", ni es sólo el doble monstruoso de la Virgen de Guadalupe (Godayol 2012, p. 66). Concierto barroco se alinea con la cultura patriarcal y hace de Malintzin, además de todo, una Judit fracasada.

Gracias a la ausencia de Judit en La aprendiz de bruja, la pertinencia de Rajab como centro mítico y poético de la pieza se explica mejor. Mientras que la historia de Judit carece de complejidad trágica (su amor por Holofernes es falso, y por lo tanto no hay dilemas morales), la de Rajab no. Aunque el léxico empleado en el monólogo de La aprendiz de bruja sugiera traición y tragedia (ruinas, ojos vendados, compromisos rotos, destrucción, una verdad aclarada demasiado tarde...), tiene la frescura de idea nueva, no alineada todavía con la narrativa imperante durante el siglo Xx. Como buen personaje trágico, la verdad de Marina está cubierta por múltiples velos. Y aun así, Marina misma se reconoce en la obra teatral como pocos habrán de reconocerla en el porvenir, marcada por la soledad y cargando consigo su narrativa y su voz.

En esta reescritura heterodoxa de la historia de Malintzin, se descubren formas de relacionar el pasado con otros tiempos. La pieza de teatro no sólo reescribe el mito del aprendiz de brujo, que da título al drama, o las narrativas coloniales, como la de Bernal Díaz del Castillo. Entre la penumbra de su presente, $L a$ aprendiz de bruja reconstruye la arqueología de Malintzin, pues cita un relato arcaico que logra fracturar el tiempo y reestructurarlo: el de Rajab, según la cuenta el libro bíblico de Josué y Dante en la Commedia. Gracias a Marina y Rajab, en estos tres textos se dan cita generaciones distanciadas por milenios. Luego de presiones diversas, y en parte por la fe en unos invasores 
al parecer divinamente ungidos, ambas mujeres, marginales pero elocuentes y astutas, abandonaron sus patrias. Como consecuencia, los pueblos en que nacieron quedaron en ruinas, pero ellas terminaron siendo salvadas por el conquistador, avaro de riquezas y poder.

Puestas una al lado de la otra, ambas historias corren paralelas con asombrosa atemporalidad. Incluso la polionomasia de Malintzin está prefigurada en Rajab: la Septuaginta la llama

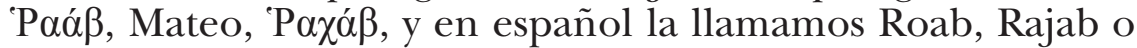
Raab (Weren 1997, p. 298). Pero este encuentro necesitó más que erudición bíblica. Hay en Dante y en la Commedia un poder catalizador que revivió a Rajab y trasladó su antigua materia exegética al ámbito literario, para hacerla contemporánea de muchos pasados. Dante, al haberla insertado en la tradición literaria occidental, permitió que Carpentier la tomara como base interpretativa de su obra.

Pero La aprendiz de bruja también critica a la Rajab rabínica y patrística de Dante. Como consecuencia de esto - quizás no premeditada-, la pieza ofrece una Malintzin más en línea con las interpretaciones chicanas del mito que con las narrativas tradicionales de los años cincuenta. Por una parte, Marina niega la creencia europea de que ella habita en el Paraíso. Cuestiona, por tanto, la idealización de América y los relatos triunfalistas de la colonia, pero sobre todo socava las tipologías simplificadoras que sostienen que sólo se puede ser santa o meretriz, madre o traidora, estar dentro del Paraíso o fuera. En la obra teatral, el personaje carga con complejidades trágicas que carecen de soluciones binarias. Pone en crisis, además, la apoteosis de la silenciosa y tranquila Rajab de la Commedia.

Mientras que para Dante, Rajab no dice una palabra y apenas se mueve, la Rajab de La aprendiz de bruja, es decir Marina, viene caracterizada por el don de la astuta elocuencia, como en Josué. El mismo título de la obra teatral lo subraya. Se moderniza aún más al personaje cuando le viene dado otro don, renacentista y barroco: la perspectiva. Apropiándose del itinerario ascendente propiamente dantesco, La aprendiz de bruja termina por refundir el personaje tradicional. Esta redención de Marina es ambivalente, asciende en un cuestionamiento panorámico y llega a una serie de interrogaciones. "¿Viví para el Bien? ¿Viví para el Mal...?” es una pregunta improcedente en la Rajab dantesca, pero que Marina se formula en el momento culminante del drama y, lo que es más importante, nunca responde. 
La Rajab mesoamericana confeccionada en La aprendiz de bruja, provista de voz, perspectiva, conciencia y ética altruista, es capaz de reconocerse en el pasado y de narrarse a sí misma.

En las fuentes principales que transmiten ambos relatos, ni Rajab ni Malintzin tienen el lujo de dudar o de hacerse preguntas. Sus interpretadores, en cambio, sí lo tienen. En dos mil años de trayectoria, Rajab ha sido narrada como mentirosa o profeta, traicionera o heroína, prostituta canaanita o madre de la Iglesia. Según unos, casó con Salmá; según otros, con Josué. En la tradición midrásica la compararon con Moisés, luego la desdeñaron los comentaristas judíos bajomedievales, y aunque los padres de la Iglesia abunden en sus menciones, el cristianismo moderno terminó olvidándola. Entre tantas figuras sobrepuestas, tiene sentido que Marina imagine a Rajab preguntándose “¿Quién soy?”. De cierta forma, y esto es más importante, está preguntando a Rajab (y a sí misma) “¿Quién eres?”. Por eso el encuentro de ambas en La aprendiz de bruja también enriquece las interpretaciones posibles sobre Malintzin con la fascinante tradición exegética de Rajab, y viceversa ${ }^{36}$. Al final no importa si en la obra se reescribieron o no fragmentos de la Commedia. Por la heterodoxia literaria de su ejercicio hermenéutico, $L a$ aprendiz de bruja ofrece puertas para revisitar la figura de Malintzin Tenepal, y para diluir las dicotomías que han limitado a esta elocuente mujer. El gesto altruista de Marina no requiere una respuesta, ni la imposición de más figuras. Sólo invita a una pregunta: ¿quién eres?37

\section{REFERENCIAS}

Adorno, Rolena 2007. The Polemics of possession in Spanish American narrative, Yale University Press, New Haven, CT.

Agamben, Giorgio 2008. Che cos'è il contemporaneo?, Nottentempo, Roma.

${ }^{36}$ Havrelock (2017, p. 254) articula ya un análisis de doble vía entre ambas figuras. Para una lectura en clave feminista y cómica de Rajab, véase JACKSON 2012; para una reescritura en primera persona, véase BRENNER 2005.

37 Agradezco a los lectores anónimos sus invaluables sugerencias y a Rolena Adorno, Stefan Lessmann, Nils Longueira y Jesús Velasco su atenta y generosa lectura, así como a Patrizia Di Patre, Roberto González Echevarría, Aníbal González-Pérez y Emilia Perassi los comentarios sobre la cuestión. Los errores que hubieran permanecido son enteramente míos. 
Alarcón, Norma 1989. "Traddutora, traditora: A paradigmatic figure of Chicana feminism”, Cultural Critique, 13, pp. 57-87; doi: 10.2307/1354269.

Alighieri, Dante 1922 [1321]. La divina comedia. Ed. Nicolás Besio Moreno. Trad. Bartolomé Mitre, Centro Cultural Latium, Buenos Aires.

Alighieri, Dante 1966-1967 [1321]. La Commedia secondo l'antica vulgata. Ed. Giorgio Petrocchi, Mondadori, Milano.

Alighieri, DAnte 2018 [1321]. La divina commedia. Ed. Enrico Malato, Salerno Editrice, Roma.

Anzaldúa, Gloria 1987. Borderlands/La frontera: The new mestiza, Spinsters/ Aunt Lute, San Francisco, CA.

BÁez-Jorge, Félix 1988. "La aprendiz de bruja: Hernán Cortés y la Malinche en el universo de Carpentier", en La Afrodita barbuda. Literatura y plástica en la perspectiva antropológica, Instituto Veracruzano de Cultura, Veracruz, 1988, pp. 101-119.

Benítez Rojo, Antonio 1983. “«El camino de Santiago» de Alejo Carpentier y el «Canon Perpetuus», de Juan Sebastián Bach: paralelismo estructural", Revista Iberoamericana, 49, 123/124, pp. 293-322; doi: 10.5195/reviberoamer.1983.3781.

BINIK, IRving M. 2018. Rahab the prostitute: A history of interpretation from Antiquity to the Medieval period, tesis, McGill University, Montréal.

Brenner, Athalya 2005. "I am Rahab, the broad", en I Am-: Biblical women tell their own stories, Fortress Press, Minneapolis, MN, pp. 82-98.

Brotherston, Gordon 1994. "La Malintzin de los códices", en La Malinche, sus padres y sus hijos. Ed. Margo Glantz, Universidad Nacional Autónoma de México, México, pp. 13-29.

Burton, Richard Eugene 1906. Rahab: A drama in three acts, Henry Holt and Company, New York.

Butler, Judith 2005. "An account of oneself", en Giving an account of oneself, Fordham University Press, New York, pp. 3-40; doi: 10.5422/ fso/9780823225033.001.0001.

Cáceres Valderrama, Milena 1982. "Sobre el título de la obra Concierto barroco de Alejo Carpentier”, Boletín del Instituto Riva-Agüero 1977-1981, pp. 21-25.

Carpentier, Alejo 1970. "Nuestro primer clásico: Bernal Díaz del Castillo", Verde Olivo, La Habana, 11, 28, 12 de julio, pp. 24-25.

Carpentier, Alejo 1983. Concierto barroco, en Obras completas, Siglo XXI, México, t. 4, pp. 145-214.

Carpentier, Alejo 1983a [1956]. La aprendiz de bruja. Trad. Carmen Vázquez, en Obras completas, Siglo XXI, México, t. 4, pp. 25-143.

Carpentier, Alejo 1983b. Obras completas. T. 1: Écue-Yamba-Ó. La rebambaramba. Cinco poemas afrocubanos. Historia de lunas. Manita en el suelo. El milagro de anaquillé, Siglo XXI, México.

Cavarero, Adriana 2000. "The paradox of Ulysses", en Relating narratives: Storytelling and selfhood. Trad. Paul A. Kottman, Routledge, London, pp. $17-31$.

Chimalpahin's conquest: A Nahua historian's rewriting of Francisco López de Gómara's "La Conquista de México" 2010. Eds. \& trans. Susan Schroeder, David E. Tavárez \& Cristian Andres Roa-de-la Carrera, Stanford University Press, Palo Alto. 
Crespo-Jaramillo, Esteban 2021. "Alejo Carpentier recuerda a Dante: heterodoxia e innovación”, en Actas del II Congreso Andino sobre Dante. Ed. Patrizia di Patre, Pontificia Universidad Católica de Ecuador, Quito, pp. 237-253.

Cypess, SANDra Messinger 1991. La Malinche in Mexican literature from history to myth, University of Texas Press, Austin.

Dartmouth Dante Project 2019. Dartmouth University, Dartmouth, en https:/ /dante.dartmouth.edu/ [consultado en agosto de 2019].

Díaz del Castillo, Bernal 2011 [1632]. Historia verdadera de la conquista de la Nueva España. Ed. Guillermo Serés, Galaxia Gutenberg-Círculo de Lectores-Real Academia Española, Barcelona-Madrid.

ELiot, T.S. 1928 [1920]. "Tradition and the individual talent", en The sacred wood: Essays on poetry and criticism, 2. ${ }^{\mathrm{a}}$ ed., Methuen \& Co., London, pp. 47-59.

Ellis, Steve 1983. Dante and English poetry: Shelley to T.S. Eliot, Cambridge University Press, Cambridge-New York.

Fernández, A. 1924. "El herem bíblico", Biblica, 5, 1, pp. 3-25.

Galzio, Cecilia 1999. "La aprendiz de bruja di Alejo Carpentier”, Studi di Letteratura Ispano-Americana, 33, pp. 161-183.

Garí Barceló, Bernat 2015. "La aprendiz de bruja de Alejo Carpentier: relectura teatralizada de la conquista de México”, Anagnórisis. Revista de Investigación Teatral, 12, pp. 136-150.

Glantz, Margo 2003. "Doña Marina and Captain Malinche", en Bilingual games. Ed. Doris Sommer, Palgrave, New York, pp. 149-161.

Godayol, Pilar 2012. "Malintzin/ la Malinche/ Doña Marina: Re-reading the myth of the treacherous translator", Journal of Iberian and Latin American Studies, 18, 1, pp. 61-76; doi: 10.1080/14701847.2012.716645.

Goethe, Johann WolfGang von 1924. "El aprendiz de brujo". Trad. Manuel Pérez y del Río-Cosa, en Hermann y Dorotea. Poesías varias, Reus, Madrid, pp. 279-281.

Goethe, Johann Wolfgang von 1957. "El aprendiz de mágico". Trad. Rafael Cansinos Assens, en Obras completas, Aguilar, Madrid, t. 4, pp. 133-135.

Goethe, Johann Wolfgang von 1997-2019. "Der Zauberlehrling”, en Goethes Werke im WWW [Goethes Werke: Herausgegeben im Auftrage der Großherzogin Sophie von Sachsen: I. Abtheilung: Goethes Literarische Werke: 1. Band, Böhlau Verlag, Weimar, 1887], base de datos, http://goethe.chadwyck. com [consultado en junio de 2021].

González Echevarría, Roberto 1990. Alejo Carpentier. The pilgrim at home, University of Texas Press, Austin.

González Echevarría, Roberto 2012. "Dante in Alejo Carpentier”, MLN Italian Issue Supplement, 127, 1, pp. S216-S224.

González-PÉrez, Aníbal 2018. "Tales from eternity: María Luisa Bombal, Alejo Carpentier, Juan Rulfo", en In search of the Sacred Book: Religion and the Contemporary Latin American Novel, University of Pittsburgh Press, Pittsburgh, PA, pp. 81-118; doi:10.2307/j.ctvgd1nj.

Haraway, Donna 2016. "A cyborg manifesto", en Manifestly Haraway. Eds. Donna Haraway \& Cary Wolfe, University of Minnesota Press, Minneapolis, pp. 5-90. 
Havrelock, Rachel 2017. "Home at last: The local domain and female power", en The Bible and feminism: Remapping the field. Ed. Yvonne Sherwood, Oxford University Press, Oxford, pp. 240-260.

Hawkins, Peter S. 2009. "Dante's Rahab”, Modern Language Notes, 124, 5, pp. S70-S80.

Iosue 1995. Eds. Alberto Colunga et Lorenzo Turrado, en Biblia Sacra Vulgatae editionis Sixti V Pontificis Maximi iussu recognita et Clementis VIII auctoritate edita, Biblioteca de Autores Cristianos-Edizioni San Paolo, Madrid-Milano, pp. 172-193.

Jackson, Melissa 2012. "Rahab", en Comedy and feminist interpretation of the Hebrew Bible: A subversive collaboration, Oxford University Press, Oxford; doi:10.1093/acprof:oso/9780199656776.003.0005.

JAMESOn, A.K. 1937. "The sources of Lope de Vega's erudition”, Hispanic Review, 5, 2, pp. 124-139; doi: 10.2307/469838.

Kallendorf, Hilaire 2007. "Introduction: The rise of casuistry in Spain, the flowering of Jesuit School drama, and the Jesuit education of Spanish playwrights", en Conscience on stage: The comedia as casuistry in Early Modern Spain, University of Toronto Press, Toronto, pp. 3-37.

LADNer, Gerhart B. 1967. "Homo viator: Mediaeval ideas on alienation and order”, Speculum, 42, 2, pp. 233-259; doi: 10.2307/2854675.

León-Portilla, Miguel (ed.) 1961. Visión de los vencidos: relaciones indígenas de la conquista. Versión de textos nahuas por Ángel M. Garibay K., ilustraciones de códices por Alberto Beltrán, Universidad Nacional Autónoma de México, México.

Lopez, Kimberle 2002. "Colonial desire and the anxiety of identification in the New Latin American Novel of the Conquest", en Latin American Novels of the Conquest: Reinventing the New World, University of Missouri Press, Columbia, pp. 1-27 [notas: pp. 179-189].

López Estrada, Francisco 1969. "Estudio sobre Fuente Ovejuna de Lope de Vega”, en Lope de Vega y Cristóbal de Monroy y Silva, Fuente ovejuna: dos comedias. Ed. Francisco López Estrada, Castalia, Madrid, pp. 9-37.

Lyons, William L. 2008. "Rahab through the ages: A study of Christian interpretation of Rahab", en Society of Biblical Literature Forum. Ed. Leonard Greenspoon, https://www.sbl-site.org/ [consultado en marzo de 2019].

Mazzotta, Giuseppe 1979. "Opus restaurationis", en Dante, poet of the desert: History and allegory in the "Divina commedia", Princeton University Press, Princeton, pp. 14-65.

Mazzotta, Giuseppe 2004. "Paradiso en el Paradiso", en Cuba. Un siglo de literatura (1902-2002). Coords. Anke Birkenmaier y Roberto González Echevarría, Editorial Colibrí, Madrid, pp. 147-163.

Moulin-Civil, Françoise 2012. "La mise en scène de l'Histoire: La aprendiz de bruja (1956) d'Alejo Carpentier", en Alejo Carpentier à l'aube du ххıе siècle. Éd. Fabrise Parisot, L’Harmattan, Paris, pp. 95-105.

Navarro Salazar, María Teresa 2006. "Le scelte dantesche di Alejo Carpentier”, Epos, 22, pp. 203-218.

NowELl, IrEnE 2008. "Jesus' great-grandmothers: Matthew's four and more", The Catholic Biblical Quarterly, 70, 1, pp. 1-15. 
Paoluchi, Anne 2004. "Dante's influence on American writers", en Dante: Beyond the "Commedia". Ed. Anne Paolucci, Griffon House, Wilmington, pp. 33-71.

Paz, Octavio 1969 [1950]. El laberinto de la soledad, $7^{\mathrm{a}}$ ed., Fondo de Cultura Económica, México.

Perassi, Emilia 2005. "Il tema preispanico nel teatro di Salvador Novo", en Temi storici nel teatro ispanoamericano, Bulzoni, Roma, pp. 101-127.

Pigman, George W. 1980. "Versions of imitation in the Renaissance", Renaissance Quarterly, 33, 1, pp. 1-32; doi: 10.2307/2861533.

Plá Cortés, Angélica A. 2014. La aprendiz de bruja: paradigma de lo mestizo en la obra de Alejo Carpentier, tesis, El Colegio de México, México, en https: / / colmex.userservices.exlibrisgroup.com/ view/ delivery/ 52COLMEX_ INST/ 1265045060002716 [consultado en agosto de 2019].

Pratt, Mary Louise 1993. "«Yo soy la Malinche»: Chicana writers and the poetics of ethnonationalism”, Callaloo, 16, 4, pp. 859-873.

Praz, Mario 1966. "T.S. Eliot and Dante", en The flaming heart: Essays on Crashaw, Machiavelli, and other studies in the relations between Italian and English literature from Chaucer to T.S. Eliot, Peter Smith, Gloucester, MA, pp. 348-373.

Raggi Rodríguez, Armando \& Rafael Rodríguez Beltrán 2016. "The bibliographical collections and archives of the Fundación Alejo Carpentier, Cuba”, Caribbean Quarterly, 62, 3/4, pp. 357-372; doi: 10.1080/00086495.2016.1260277.

Restall, Matthew 2018. When Montezuma met Cortés: The true story of the meeting that changed history, Harper Collins Publishers, New York.

Reyes, Alfonso 1953. Visión de Anáhuac (1519), El Colegio de México, México.

Reyna, Cassiodoro de (trad.) 1569. La Biblia, que es los sacros libros del Viejo y Nuevo Testamento, [Samuel Apiarius-Thomas Guarinus], Basilea.

Robinson, Bernard P. 2009. "Rahab of Canaan-and Israel", Scandinavian Journal of the Old Testament, 23, 2, pp. 257-273; doi:10.1080/09018320903303603.

Rodríguez Monegal, Emir 1982. "Historia y ficción en Carpentier y Borges", Revista de la Universidad de México (nueva época), 9, pp. 8-13.

Rosso, G. ANTHONy 2012. "The last strumpet: Harlotry and hermaphroditism in Blake's Rahab”, en Blake, gender and culture. Ed. Helen Bruder, Routledge, London, pp. 25-36; doi: 10.4324/9781315655130.

Rosso, G. Anthony 2016. The religion of empire: Political theology in Blake's prophetic symbolism, Ohio State University Press, Columbus, $\mathrm{OH}$.

Rowlett, Lori L. 2000. "Disney's Pocahontas and Joshua's Rahab in postcolonial perspective", en Culture, entertainment, and the Bible. Ed. George Aichele, Bloomsbury Publishing, London, pp. 66-75.

Sölle, Dorothee 1994. Great women of the Bible in art and literature. Pref. by Herbert Haag. Trad. Joe H. Kirchberger. Ed. Emil Bührer, Mercer University Press, Macon.

Tafolla, Carmen 1993. "La Malinche", en Infinite divisions: An anthology of Chicana literature. Eds. Tey Diana Rebolledo \& Eliana S. Rivero, University of Arizona Press, Tucson, pp. 198-199. 
Townsend, Camilla 2003. "Burying the white gods: New perspectives on the Conquest of Mexico", The American Historical Review, 108, 3, pp. 659687; doi: $10.1086 / 529592$.

Townsend, Camilla 2006. Malintzin's choices: An indian woman in the Conquest of Mexico, University of New Mexico Press, Albuquerque.

VÁsquez, CARmen 2003. "Renacimiento y memoria de la escritura. Pasos perdidos y encontrados en Tierra Firme", América: Cahiers du CRICCAL, 30, pp. 169-176; doi:10.3406/ameri.2003.1618.

VÁzQuez, CARMen 1986. "La aprendiz de bruja: drama en tres actos de Alejo Carpentier”, Revista de Estudios Hispánicos, 13, pp. 53-70.

Vindel, Francisco 1930. Manual gráfico-descriptivo del bibliófilo hispano-americano: (1475-1850), t. 3, Imprenta Góngora, Madrid.

Volek, Emil 1996. "La conquista de América en el teatro posmoderno", en El teatro y sus claves: estudios sobre teatro argentino e iberoamericano. Ed. Osvaldo Pellettieri, Editorial Galerna-Facultad de Filosofía y Letras (UBA), Buenos Aires.

Weren, Wim J.C. 1997. "The five women in Matthew's genealogy”, The Catholic Biblical Quarterly, 59, 2, pp. 288-305. 